Tropical Journal of Pharmaceutical Research May 2021; 20 (5): 939-946

ISSN: $1596-5996$ (print); 1596-9827 (electronic)

(C) Pharmacotherapy Group, Faculty of Pharmacy, University of Benin, Benin City, 300001 Nigeria.

\title{
MiR-875-5p suppresses cervical cancer cell proliferation and metastasis via negative regulation of EGFR
}

\author{
Hua Liang, Yuzi Zhao, Jie Pi, Ruoyu Luo* \\ Department of Obstetrics \& Gynecology, Renmin Hospital of Wuhan University, Wuhan City, Hubei Province 430060, China
}

*For correspondence: Email: ruoyuluo8@163.com; Tel: +86-027-88041911

Sent for review: 3 March 2021

Revised accepted: 30 April 2021

\begin{abstract}
Purpose: To explore miRNA-875-5p and epidermal growth factor receptor (EGFR) activities in tissues or cells from cervical cancer, and their underlying molecular mechanisms.

Methods: Tissues were obtained from cervical cancer patients and their miR-875-5p expression was determined by quantitative reverse transcription-polymerase chain reaction (qRT-PCR). Caski or HeLa cells were transfected with miR-875-5p mimics or miR-875-5p inhibitor to assess the effect of miR-875$5 p$ expression on cell viability, cell cycle, migration, and invasion using Cell Counting Kit-8 (CCK-8), flow cytometry, wound healing, and Transwell assays. Potential target genes of miR-875-5p were predicted and verified using a dual luciferase reporter assay. In addition, EGFR expression was evaluated by western blot.

Results: MicroRNA-875-5p was expressed at low levels in cervical cancer tissues and was related to FIGO stage, lymph node metastasis, pathological grade, vascular involvement, and deep stromal invasion in patients with cervical cancer. MicroRNA-875-5p overexpression inhibited cell viability, migration, and invasion, and caused GO/G1 phase block of Caski and HeLa cells. Moreover, EGFR was the target gene of miR-875-5p and was negatively regulated by miR-875-5p. Reductions in cell viability, migration, invasion, and the number of G0/G1-phase cells were inhibited by EGFR overexpression. Conclusion: MiR-875-5p suppresses cervical cancer cell growth and metastasis by negatively regulating EGFR. Therefore, miR-875-5p can potentially be exploited for the management of cervical cancer.
\end{abstract}

Keywords: MiR-875-5p, EGFR, Cell viability, Cell cycle, Cell migration, Cell invasion

\begin{abstract}
This is an Open Access article that uses a fund-ing model which does not charge readers or their institutions for access and distributed under the terms of the Creative Commons Attribution License (http://creativecommons.org/licenses/by/4.0) and the Budapest Open Access Initiative (http://www.budapestopenaccessinitiative.org/read), which permit unrestricted use, distribution, and reproduction in any medium, provided the original work is properly credited.

Tropical Journal of Pharmaceutical Research is indexed by Science Citation Index (SciSearch), Scopus, International Pharmaceutical Abstract, Chemical Abstracts, Embase, Index Copernicus, EBSCO, African Index Medicus, JournalSeek, Journal Citation Reports/Science Edition, Directory of Open Access Journals (DOAJ), African Journal Online, Bioline International, Open-J-Gate and Pharmacy Abstracts
\end{abstract}

\section{INTRODUCTION}

Cervical cancer is second to breast cancer as the most common gynecologic malignancy [1]. The incidence of cervical cancer has been increasing and tending toward younger ages over the past decade [2]. The course of cervical cancer generally involves cervical hyperplasia, early invasive carcinoma, and cervical cancer [2]. More than $50 \%$ of patients have progressed to invasive carcinoma by the time they are diagnosed, and at this stage invasion and metastasis greatly reduce their survival. Moreover, patients with cervical cancer usually have a poor prognosis and lower survival rate, and the underlying pathological mechanisms of 
cervical cancer are complex [3]. Therefore, it is important to identify biomarkers that influence the development of cervical cancer. MicroRNAs (miRNAs) regulate gene expression through the post-transcriptional regulation of the translation of control mRNAs [4]. In cervical cancer, miRNAs have also been reported to act as biomarkers, oncogenes, and tumor suppressors regulating cervical carcinogenesis, metastasis, or apoptosis [5-7]. Weng et al. found that miR-875-5p was highly expressed in renal clear cell carcinoma and at much higher levels than other miRNAs [4]. MicroRNA-875 and miR-3144 suppress the expression of E6 oncogene and HPV16-positive cells, which are common in cervical cancer, suggesting that miR-875 might have a tumorsuppressing effect [8]. However, the mechanism of action of miR-875-5p on cervical cancer cells is still unclear. Epidermal growth factor receptor (EGFR) is a cell membrane protein that is widely distributed in human tissues [9]. Epidermal growth factor receptor is overexpressed, amplified, or mutated in various epithelial tumor cells and is closely associated with tumor aggressiveness and resistance to treatment [10]. Overexpression of EGFR in malignant cells induces autocrine factors in tumor cells [10]. The abnormal expression of EGFR has also been shown to influence the progression of cervical cancer [11]. Nonetheless, the specific regulatory mechanisms involved in the effects of miR-875$5 p$ and EGFR on cervical cancer are not known.

In this study, the biological functions of miR-875$5 p$ and its potential molecular mechanisms in cervical cancer cells were investigated by in vitro cell experiments, with the aim of seeking new therapeutic avenues for cervical cancer.

\section{METHODS}

\section{Tissue collection}

Thirty-seven patients admitted to Renmin Hospital of Wuhan University who had a postoperative histopathological diagnosis of cervical cancer were selected as the cancer group. Patients with other types of tumors or with cardiac, hepatic, renal, or other vital organ disease were excluded. The average age of the patients with cervical cancer was $46.29 \pm 5.33$ years, and other clinical information about these patients is shown in Table 1. In addition, 33 patients with suspected cervical cancer and a histopathological diagnosis of a normal cervix, average age $51.08 \pm 6.21$ years, were selected as the control group. Cervical tissue specimens were collected from the cancer and control groups for surgical resection or biopsy, and stored at $-80{ }^{\circ} \mathrm{C}$ for subsequent experiments.
The experiment was approved by the Medical Ethics Committee of Renmin Hospital of Wuhan University (approval no. 2019113), and informed consent was obtained from patients or their families.

\section{Cell culture and transfection}

Human cervical cancer epithelial Caski cells (CL0048, Procell, Wuhan, China) were cultured in Roswell Park Memorial Institute (RPMI) Medium 1640 (Procell) with $10 \%$ fetal bovine serum (FBS, Procell) and $1 \%$ penicillin/streptomycin (P/S, Procell) at $37^{\circ} \mathrm{C}$. Human cervical cancer HeLa cells (CL-0101, Procell) were cultured in minimum essential medium (MEM, Procell) with $10 \% \mathrm{FBS}$ and $1 \% \mathrm{P} / \mathrm{S}$ at $37^{\circ} \mathrm{C}$. Logarithmic Caski or HeLa cells were harvested for transfection with miR-875-5p mimic, miR-875-5p inhibitor, or pcDNA3.1-EGFR (Invitrogen, Carlsbad, CA, USA), using Lipofectamine 3000 (Thermo Fisher Scientific, Waltham, MA, USA).

\section{Cell viability assay}

Caski or HeLa cells were treated with Cell Counting Kit-8 solution (CCK-8, Solarbio, Beijing, China) and co-incubated for $1 \mathrm{~h}$ at $37^{\circ} \mathrm{C}$. The optical density (OD) was measured at $450 \mathrm{~nm}$ using a microplate reader (Shanghai Aucy Scientific Instrument, China).

\section{Cell cycle assay}

Transfected cells were digested with $0.25 \%$ trypsin reagent (Sigma-Aldrich, St. Louis, MO, USA) and fixed in anhydrous ethanol at $4{ }^{\circ} \mathrm{C}$ for 30 min. Phosphate-buffered saline (PBS, SigmaAldrich) was used to wash fixed cells. The treated cells were incubated with $0.25 \mathrm{mg} / \mathrm{ml}$ RNAse (Thermo Fisher Scientific) at $37^{\circ} \mathrm{C}$ for 30 min. Propidium iodide $(\mathrm{PI})$ staining solution was added to cells for $30 \mathrm{~min}$ in the dark. The proportion of cells at different stages of the cell cycle was determined using flow cytometry (Beckman Coulter, USA).

\section{Cell migration assay}

After evenly scribing at least 5 lines per well on the back of a 6 -well plate, transfected cells were added to plates and incubated overnight. After horizontal lines were scratched in the cell layer with a pipette tip held perpendicular to the plate, the cells were washed with PBS and incubated in serum-free medium for $24 \mathrm{~h}$. The plates were photographed, and the relative wound width was calculated using Image J software (NIH Image, Bethesda, MD, USA). 


\section{Cell invasion assay}

Matrigel (Sigma-Aldrich) was added to the upper chamber of the Transwell unit, and serumcontaining medium was added to the lower chamber. Transfected cells were incubated in the upper Transwell chamber overnight. The upper chambers were removed, and cells in the lower chamber were washed and stained with $0.1 \%$ crystal violet (Beyotime, Shanghai, China). These invading cells were observed and counted using a microscope (Leica Microsystems, Weitzlar, Germany).

\section{Dual luciferase reporter assay}

The plasmids pGL3-EGFR-wild type (WT) and pGL3-EGFR-mutant (MUT) were obtained from Genechem (Shanghai, China). HeLa cells were co-transfected with miR-875-5p mimics or NC mimics and pGL3-EGFR-WT or pGL3-EGFRMUT for $24 \mathrm{~h}$, washed with PBS, and treated with Passive Lysis Buffer (Promega Corporation, Madison, WI, USA), while shaking, for $15 \mathrm{~min}$. The relative luciferase activity was measured using the Dual-Luciferase ${ }^{\circledR}$ Reporter Assay System Protocol (Promega).

\section{Reverse-transcription polymerase chain reaction (qRT-PCR)}

Total RNA was extracted from cancer tissues or transfected cells, and PCR amplification was performed using Quant One Step qRT-PCR Kit (Probe, Bjbalb, Beijing, China). The conditions of PCR amplification were: pre-denaturation at 92 ${ }^{\circ} \mathrm{C}$ for $3 \mathrm{~min}$; denature at $92{ }^{\circ} \mathrm{C}$ for $10 \mathrm{~s}$, anneal at $50{ }^{\circ} \mathrm{C}$ for $20 \mathrm{~s}$, extend at $68{ }^{\circ} \mathrm{C}$ for $20 \mathrm{~s}$, repeated 35 times; extension at $68{ }^{\circ} \mathrm{C}$ for $8 \mathrm{~min}$. The sequences of miR-875-5p and glyceraldehyde-3-phosphate dehydrogenase (GAPDH) primers are shown in Table 1.

Table 1: Primer sequences

\begin{tabular}{|c|c|c|}
\hline Primer & $\begin{array}{l}\text { Forward/ } \\
\text { Reverse }\end{array}$ & Sequence (5'-3') \\
\hline \multirow[t]{2}{*}{$\begin{array}{l}\text { MiR-875- } \\
5 p\end{array}$} & $\mathrm{~F}$ & $\begin{array}{l}\text { TATACCTCAGTTTTATCAG } \\
\text { GTG }\end{array}$ \\
\hline & $\mathrm{R}$ & $\begin{array}{l}\text { CCTGATAAAACTGAGGTAT } \\
\text { ATT }\end{array}$ \\
\hline \multirow[t]{2}{*}{ GAPDH } & $\mathrm{F}$ & $\begin{array}{l}\text { TGAACGGGAAGCTCACTG } \\
\text { G }\end{array}$ \\
\hline & $\mathrm{R}$ & $\begin{array}{l}\text { TCCACCACCCTGTTGCTGT } \\
\text { A }\end{array}$ \\
\hline
\end{tabular}

\section{Western blot}

Cellular proteins were extracted from transfected Caski or HeLa cells using lysis buffer (SigmaAldrich). The protein concentrations were measured using the Bradford method. The proteins were separated by sodium dodecyl sulfate polyacrylamide gel electrophoresis (SDSPAGE) and transferred to nitrocellulose (NC) membranes. The proteins were co-incubated with primary antibodies, anti-EGFR (1:2000, ab52894, Abcam, Cambridge, MA, USA) and anti- $\beta$-actin (1:1500, ab8227, Abcam), for $16 \mathrm{~h}$ at $4^{\circ} \mathrm{C}$. After washing with PBS, the proteins were incubated with horseradish peroxidase (HP)labeled secondary antibody (ab191866, Abcam) for $1 \mathrm{~h}$. The protein bands on NC membranes were visualized with color developing agent and recorded using an imaging system. The bands were analyzed using Quantity One software (NIH Image, USA).

\section{Statistical analysis}

The experimental data were calculated as mean \pm standard deviation (SD) of at least three independent experiments, and correlation analyses were performed. The results were analyzed by analysis of variance (ANOVA) using SPSS 21.0 software (SPSS Inc, USA). Values of $p<0.05$ were considered statistically significant.

\section{RESULTS}

\section{MicroRNA-875-5p expression was down- regulated in cervical cancer}

In this study, tissues were obtained from 37 cervical cancer patients. Reverse-transcription polymerase chain reaction results in Figure 1 showed that miR-875-5p expression was reduced in the cancer group, compared with the normal group, in cervical cancer $(p<0.001)$.

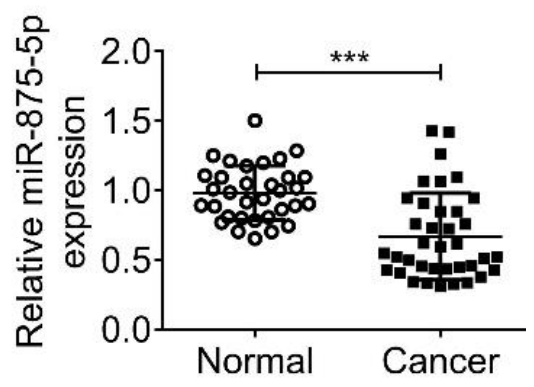

Figure 1: MicroRNA-875-5p was down-regulated in cervical cancer tissues. The miR-875-5p expression level in cervical cancer tissues $(n=37)$ and normal cervical tissues $(n=33)$ was evaluated using qRTPCR; ${ }^{* * *} p<0.001$

As shown in Table 2, the miR-875-5p level correlated with pathological grade, Federation International of Gynecology and Obstetrics (FIGO) stage, lymph node metastasis, vascular 
involvement, and deep stromal invasion in cervical cancer patients $(p<0.05)$.

\section{MicroRNA-875-5p proliferation and cancer}

To study the regulatory effects of miR-875-5p on cervical cancer cells, miR-875-5p mimic or miR875-5p inhibitor was transfected into Caski and HeLa cells. As Figure 2 A shows, cell viability was improved with miR-875-5p mimic compared to the miR-NC mimic $(p<0.001)$. In contrast, cell viability with miR-875-5p inhibitor was reduced compared to miR-NC inhibitor, and the magnitude of these reductions increased over time $(p<0.001)$. Similarly, miR-875-5p overexpression slowed the growth of Caski and HeLa cells by increasing the number of G0/G1phase cells and decreasing S- and G2/M-phase cell numbers ( $p<0.05$, Figure 2 B). However, when miR-875-5p was knocked down, the number of G0/G1-phase cells decreased significantly, whereas the number of $S$ - and G2/M-phase cells was increased $(p<0.01$, Figure $2 \mathrm{~B}$ and $2 \mathrm{C}$ ). In addition, (Figure $3 \mathrm{~A}$ ), the relative wound width in Caski and HeLa cells was increased by miR-875-5p mimic $(p<0.01)$ but reduced by miR-875-5p inhibitor $(p<0.01)$. Moreover, miR-875-5p mimic significantly decreased cell invasion in Caski and HeLa cells $(p<0.01)$, but miR-875-5p inhibitor significantly increased cell invasion ( $p<0.01$, Figure 3 B).
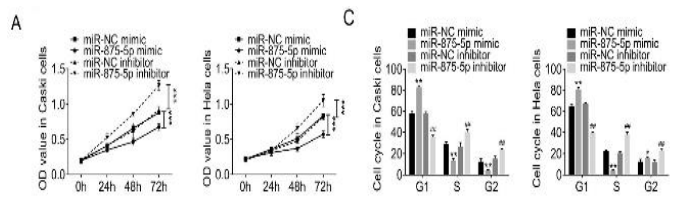

B
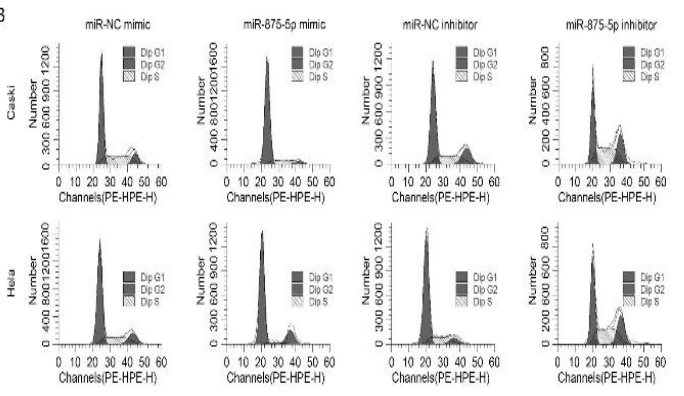

Figure 2: MicroRNA-875-5p inhibited cell viability and caused cell cycle arrest. (A) Cell viability was examined using CCK-8 assay in cells transfected with $875-5 p$ mimic or $875-5 p$ inhibitor. OD: optical density. (B-C) Cell cycle was examined using flow cytometry in cells transfected with miR-875-5p mimic or miR-875$5 p$ inhibitor; "compared with miR-NC mimic; " $p<0.05$, ${ }^{* *} p<0.01,{ }^{* * *} p<0.001$; ${ }^{*}$ compared with miR-NC inhibitor, ${ }^{\#} p<0.01$
A
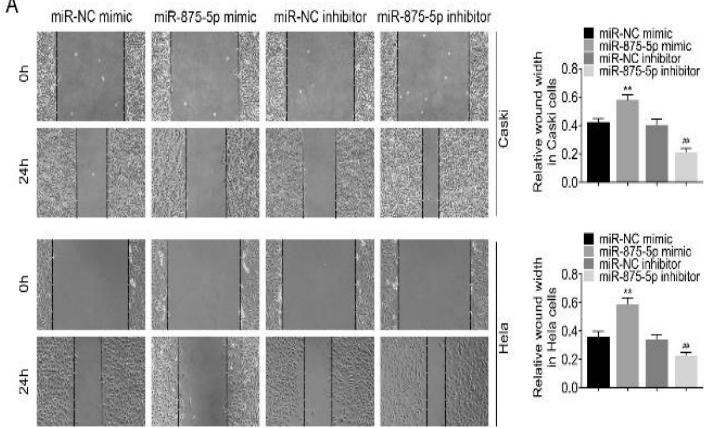

B
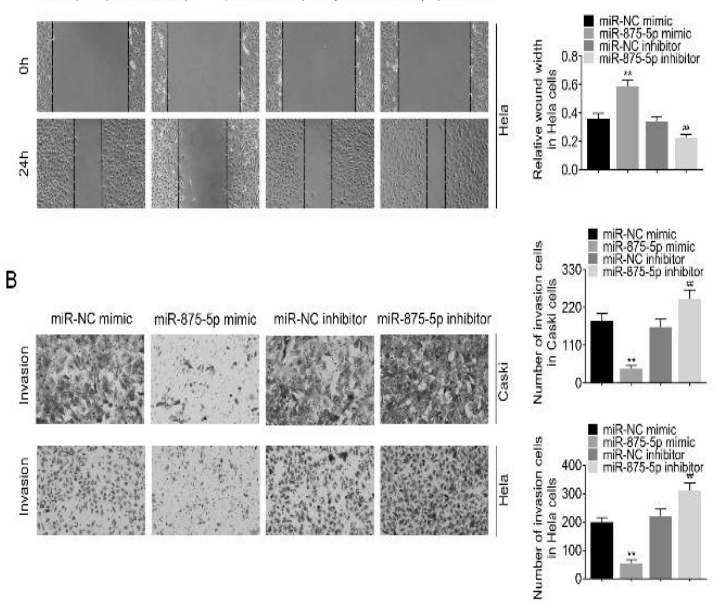

Figure 3 MicroRNA-875-5p inhibited cell migration and invasion. (A) Cell migration was examined using a wound healing assay in Caski or HeLa cells transfected with miR-875-5p mimic or miR-875-5p inhibitor. (B) Cell invasion was examined using a Transwell assay in Caski or HeLa cells transfected with miR-875-5p mimic or miR-875-5p inhibitor. denotes the results compared with miR-NC mimic, ${ }^{* *} p$ $<0.01$; \# denotes the results compared with miR-NC inhibitor, ${ }^{\#} p<0.01$

\section{EGFR was a target gene of miR-875-5p}

To better investigate the mechanism of the effect of miR-875-5p on cervical cancer cells, this study used the Targetscan website to predict target genes that could bind to miR-875-5p and found target sites between EGFR and miR-875-5p (Figure $4 \mathrm{~A}$ ). Furthermore, the results of dual luciferase reporter assays (Figure $4 \mathrm{~B}$ ) showed that luciferase intensity was significantly reduced in cells co-transfected with the miR-875-5p mimic and EGFR-WT $(p<0.01)$, while the intensity changed very little in cells co-transfected with EGFR-MUT. In addition, luciferase intensity was increased when cells were co-transfected with miR-875-5p inhibitor and EGFR-WT and was almost unchanged in EGFR-MUT co-transfected cells. Moreover, western blot results (Figure $4 \mathrm{C}$ ) showed that overexpression of miR-875-5p decreased the level of EGFR expression, whereas knockdown of miR-875-5p increased the level of EGFR expression $(p<0.01)$. The results of the correlation analysis showed that EGFR was negatively correlated with the expression of miR-875-5p (Figure 4 D). 
Table 2: Relationship between miR-875-5p expression and clinicopathological parameters in patients with cervical cancer

\begin{tabular}{|c|c|c|c|c|}
\hline Characteristics & No. of patients & $\begin{array}{l}\text { Low expression of } \\
\text { miR-875-5p } \\
(\leq \text { median })\end{array}$ & $\begin{array}{c}\text { High expression of } \\
\text { miR-875-5p } \\
\text { (> median) }\end{array}$ & $P$-value \\
\hline Number & 37 & 19 & 18 & \\
\hline Age (years) & & & & 0.419 \\
\hline$<40$ & 21 & 12 & 9 & \\
\hline$\geq 40$ & 16 & 7 & 9 & \\
\hline FIGO stage & & & & $0.031^{*}$ \\
\hline IB & 20 & 7 & 13 & \\
\hline IIA & 17 & 12 & 5 & \\
\hline Pathological grade & & & & $0.030^{*}$ \\
\hline Grade 1 & 14 & 4 & 10 & \\
\hline Grade 2 & 19 & 11 & 8 & \\
\hline Grade 3 & 4 & 4 & 0 & \\
\hline SCC-Ag (ng/ml) & & & & 0.642 \\
\hline$<4$ & 24 & 13 & 11 & \\
\hline$\geq 4$ & 13 & 6 & 7 & \\
\hline Tumor size (cm) & & & & 0.772 \\
\hline$<4$ & 28 & 14 & 14 & \\
\hline$\geq 4$ & 9 & 5 & 4 & \\
\hline $\begin{array}{l}\text { Lymph node } \\
\text { metastasis }\end{array}$ & & & & $0.027^{*}$ \\
\hline Negative & 22 & 8 & 14 & \\
\hline Positive & 15 & 11 & 4 & \\
\hline $\begin{array}{l}\text { Vascular } \\
\text { involvement }\end{array}$ & & & & $0.001^{*}$ \\
\hline Negative & 20 & 5 & 15 & \\
\hline Positive & 17 & 14 & 3 & \\
\hline $\begin{array}{l}\text { Deep stromal } \\
\text { invasion }\end{array}$ & & & & $0.003^{*}$ \\
\hline$<66 \%$ & 24 & 8 & 16 & \\
\hline$\geq 66 \%$ & 13 & 11 & 2 & \\
\hline
\end{tabular}

A
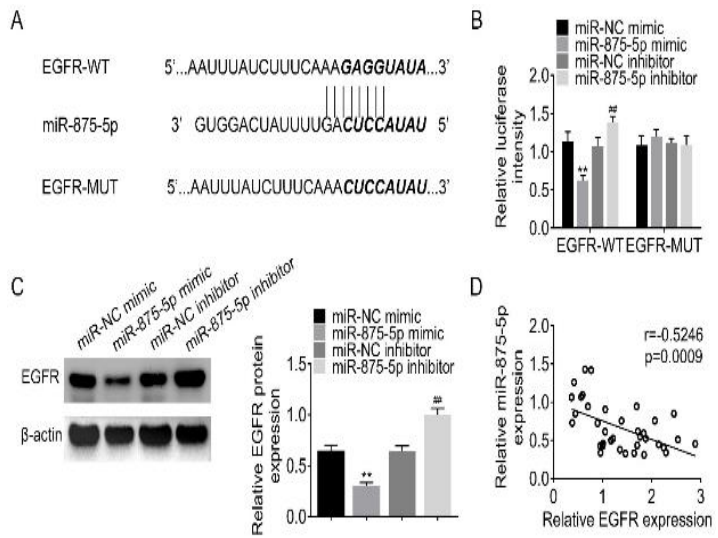

Figure 4: EGFR was a target gene of miR-875-5p. (A) The target relationship between miR-875-5p and EGFR was predicted using the Targetscan website (http://www.targetscan.org). (B) Relative luciferase was analyzed using dual luciferase reporter assays to verify the target relationship between miR-875-5p and EGFR. (C) The EGFR expression level was examined by western blot in cells transfected with miR-875-5p mimic or miR-875-5p inhibitor. (D) The relationship of miR-875-5p and EGFR was analyzed by correlation analysis. "Compared with miR-NC mimic, ${ }^{* *} p<0.01$; ${ }^{\#}$ compared with miR-NC inhibitor, ${ }^{\#} p<0.01$

\section{MicroRNA-875-5p inhibited cell proliferation and metastasis by targeting EGFR}

This study further investigated the co-regulatory effects of miR-875-5p and EGFR on cervical cancer cells. The expression of EGFR (Figure 5 A) was clearly decreased in cells co-transfected with miR-875-5p mimic + vector, whereas EGFR expression was increased by co-transfection with miR-NC + EGFR $(p<0.01)$. Furthermore, these effects on EGFR expression level were also additive in cells co-transfected with miR-875-5p mimic + EGFR, meaning both the negative effect of miR-875-5p and the positive effect of EGFR were evident $(p<0.01)$, suggesting that miR875-5p mimic and EGFR vector were both successfully transfected into cells. Overexpression of EGFR decreased cell viability (Figure $5 \mathrm{~B}$ ), while it also inhibited the increase in cell viability produced by overexpression of miR875-5p $(p<0.001)$.

Flow cytometry results (Figure $5 \mathrm{C}$ and D) showed that EGFR overexpression decreased the number of G0/G1-phase cells and increased the number of S-phase cells $(p<0.01)$. At the same time, the increase in G0/G1-phase cell number caused by miR-875-5p overexpression 
was mitigated by transfection with EGFR vector $(p<0.01)$. In the wound healing experiment shown in Figure $5 \mathrm{E}$, the relative wound width in cells co-transfected with miR-NC + EGFR was significantly reduced compared to miR-NC + vector $(p<0.01)$. Moreover, the increase in relative wound width caused by miR-875-5p overexpression was decreased by cotransfection of EGFR vector $(p<0.01)$. In addition, in cell invasion assays (Figure $5 \mathrm{~F}$ ), EGFR overexpression increased the number of invading cells, while it inhibited the reduction in invasive cell number induced by miR-875-5p overexpression $(p<0.01)$.

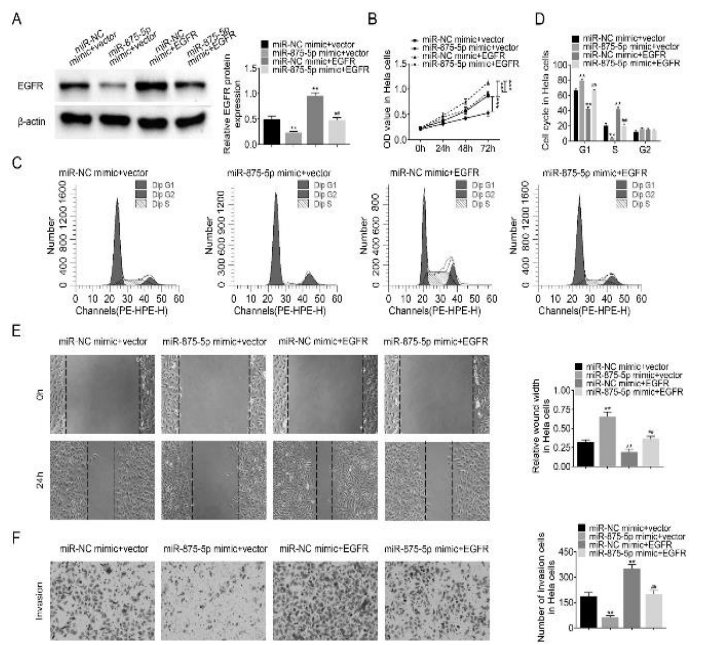

Figure 5: Overexpression of EGFR reversed the effects of miR-875-5p overexpression on cervical cancer cells. MicroRNA-875-5p mimic or miR-875-5p inhibitor and EGFR vector were co-transfected into HeLa cells. (A) The expression level of EGFR in cells co-transfected with miR-875-5p mimic and EGFR vector was examined by western blot. (B) Viability of cells co-transfected with miR-875-5p mimic and EGFR vector was examined using the CCK-8 assay. (C-D) Cell cycle was measured using flow cytometry in cells co-transfected with miR-875-5p mimic + EGFR. (E) Migration of cells co-transfected with miR-875-5p mimic + EGFR was examined using wound healing assays. (F) Cell invasion was measured using a Transwell assay. " denotes the results compared with miR-NC mimic + vector, ${ }^{* *} p<0.01,{ }^{* * *} p<0.001$; \# denotes the results compared with miR-875-5p mimic + EGFR, ${ }^{\#} p<0.01$

\section{DISCUSSION}

The etiology of cervical cancer is closely related to chromosomal mutations, human papilloma virus infection, and single nucleotide polymorphisms, especially abnormal expression of miRNA [5-7]. MicroRNA-875-5p acts as a tumor suppressor gene to inhibit progression of a variety of tumors, by targeting different target genes. MicroRNA-875-5p is rarely reported in cervical cancer. A study of pancreatic cancer found that miR-875-5p was significantly lower in tissues adjacent to cancer [12]. Like the previous study, the present study found that miR-875-5p was expressed at low levels in cervical cancer tissues, suggesting that miR-875-5p might play an oncogenic role in cervical cancer. In addition, this study also showed that the expression of miR-875-5p in cervical cancer tissues was correlated with several clinicopathological parameters, suggesting that under-expression of miR-875-5p might promote the development of cervical cancer.

Further results from this study showed that miR$875-5 p$ suppressed cell viability and metastasis and promoted cell cycle block, confirming that miR-875-5p is a tumor suppressor gene for cervical cancer. The mechanism by which miR$875-5 p$ inhibits tumors may be that it suppresses the translation or degradation of target genes, and then binds the target gene mRNAs to form an interconnected regulatory network, thereby regulating mRNA expression [13].

Epidermal growth factor receptor is activated by epidermal growth factor, which affects cell growth and differentiation. Studies have shown that EGFR is overexpressed or aberrantly expressed in various tumors, including cervical cancer [11]. Epidermal growth factor receptor and tumor cell proliferation, tumor invasion, and infiltration may have bidirectional regulatory effects [14]. Immunohistochemical detection of EGFR expression in cervical cancer tissues revealed that EGFR protein expression gradually increased with clinical stage and with increasing incidence of positivity [15]. Some miRNAs, such as miR-125a-5p and miR-2861, can also regulate the proliferative activity and apoptosis of cervical cancer cells by regulating the expression of EGFR [16].

In order to better understand the potential mechanism of miR-875-5p, this study used the Targetscan website to predict the direct binding of miR-875-5p to the EGFR 3'-UTR, and validated that EGFR was a direct target of miR875-5p. In addition, the correlation analysis found that miR-875-5p in cervical cancer was negatively correlated with EGFR expression, indicating that miR-875-5p expression negatively regulates EGFR expression. This finding presumably indicated the potential involvement of EGFR in miR-875-5p-mediated development of cervical cancer. The results of this study showed that the suppression of cell viability, migration, and invasion were alleviated by EGFR overexpression, suggesting that EGFR is indeed involved in the mechanism of cervical cancer 
mediation by miR-875-5p. To be precise, miR875-5p affected cervical cancer cell proliferation and metastasis by binding to the 3' UTR of $E G F R$, reducing the protein expression of EGFR.

\section{CONCLUSION}

MicroRNA-875-5p is expressed at low levels and is negatively correlated with EGFR expression. It inhibits cell growth and metastasis in cervical cancer by suppressing EGFR expression. These findings not only expand the molecular mechanisms of cervical cancer development but also provide new targets for cervical cancer treatment. Future studies should examine the expression of signaling molecules downstream of miR-875-5p/EGFR.

\section{DECLARATIONS}

\section{Acknowledgement}

This work was supported by the Scientific Research Project of Health Commission of Hubei Province. (Grant no. WJ2019M192).

\section{Conflict of interest}

No conflict of interest is associated with this work.

\section{Contribution of authors}

Hua Liang and Yuzi Zhao designed the study and supervised the data collection. Jie $\mathrm{Pi}$ analyzed and interpreted the data. Ruoyu Luo prepared the manuscript for publication and reviewed the draft of the manuscript. All authors have read and approved the manuscript.

\section{Open Access}

This is an Open Access article that uses a funding model which does not charge readers or their institutions for access and distributed under the terms of the Creative Commons Attribution License (http://creativecommons.org/licenses/by/ 4.0) and the Budapest Open Access Initiative (http://www.budapestopenaccessinitiative.org/rea d), which permit unrestricted use, distribution, and reproduction in any medium, provided the original work is properly credited.

\section{REFERENCES}

1. Parkin DM, Bray F, Ferlay J, Pisani P. Estimating the world cancer burden: Globocan 2000. Int J Cancer 2001; 94(2): 153-156.
2. De Martel C, Ferlay J, Franceschi S, Vignat J, Bray F, Forman D, Plummer M. Global burden of cancers attributable to infections in 2008: a review and synthetic analysis. Lancet Oncol 2012; 13(6): 607-615.

3. Dueñas-González A, Campbell S. Global strategies for the treatment of early-stage and advanced cervical cancer. Curr Opin Obstet Gynecol 2016; 28(1): 11-17.

4. Weng L, Wu X, Gao H, Mu B, Li X, Wang JH, Guo C, Jin $J M$, Chen Z, Covarrubias M. MicroRNA profiling of clear cell renal cell carcinoma by whole-genome small RNA deep sequencing of paired frozen and formalin-fixed, paraffin-embedded tissue specimens. J Pathol 2010; 222(1): 41-51.

5. Liu L, Yu X, Guo X, Tian Z, Su M, Long $Y$, Huang $C$, Zhou $F$, Liu M, Wu X. miR-143 is downregulated in cervical cancer and promotes apoptosis and inhibits tumor formation by targeting Bcl-2. Mol Med Rep 2012; 5(3): 753-760

6. Xie H, Zhao Y, Caramuta S, Larsson C, Lui W-O. miR205 expression promotes cell proliferation and migration of human cervical cancer cells. PLoS One 2012; 7(10): e46990.

7. Zhu X, Er K, Mao C, Yan Q, Xu H, Zhang Y, Zhu J, Cui F, Zhao W, Shi H. miR-203 suppresses tumor growth and angiogenesis by targeting VEGFA in cervical cancer. Cell Physiol Biochem 2013; 32(1): 64-73.

8. Lin L, Cai Q, Zhang $X$, Zhang $H$, Zhong $Y, X u C, L i Y$. Two less common human microRNAs miR-875 and miR-3144 target a conserved site of E6 oncogene in most high-risk human papillomavirus subtypes. Protein \& cell 2015; 6(8): 575-588.

9. Fischer OM, Hart S, Gschwind A, Ullrich A. EGFR signal transactivation in cancer cells. Biochem Soc Trans 2003; 31(6): 1203-1208.

10. Freed DM, Bessman NJ, Kiyatkin A, Salazar-Cavazos E, Byrne PO, Moore JO, Valley CC, Ferguson KM, Leahy $D J$, Lidke DS. EGFR ligands differentially stabilize receptor dimers to specify signaling kinetics. Cell 2017; 171(3): 683-695.

11. He C, Mao D, Hua G, Lv X, Chen X, Angeletti PC, Dong $\mathrm{J}$, Remmenga SW, Rodabaugh $\mathrm{KJ}$, Zhou J. The Hippo/YAP pathway interacts with EGFR signaling and $H P V$ oncoproteins to regulate cervical cancer progression. EMBO Mol Med 2015; 7(11): 1426-1449.

12. Gu J, Chen Y, Li S, Li Y. Identification of responsive gene modules by network-based gene clustering and extending: application to inflammation and angiogenesis. BMC Syst Biol 2010; 4(1): 47.

13. Marin JJ, Bujanda L, Banales JM. MicroRNAs and cholestatic liver diseases. Curr Opin Gastroenterol 2014; 30(3): 303-309.

14. Jacobs JM, Traeger L, Eusebio J, Simon NM, Sequist LV, Greer JA, Temel JS, Pirl WF. Depression, inflammation, and epidermal growth factor receptor (EGFR) status in metastatic non-small cell lung cancer: A pilot study. J Psychosom Res 2017; 99: 28.

15. De Almeida VH, de Melo AC, Meira DD, Pires AC, Nogueira-Rodrigues A, Pimenta-Inada HK, Alves FG, 
Moralez G, Thiago LS, Ferreira CG. Radiotherapy modulates expression of EGFR, ERCC1 and p53 in cervical cancer. Braz J Med Biol Res 2018; 51(1): e6822

16. Cao Q, Wang N, Ren L, Tian J, Cheng H. miR-125a-5p post-transcriptionally suppresses GALNT7 to inhibit proliferation and invasion in cervical cancer cells via the EGFR/PI3K/AKT pathway. Cancer Cell Int 2020; 20(1): 117. 